\title{
THE RELATIONSHIP BETWEEN THE MYDRIATIC ACTION OF EPHEDRINE AND THE COLOUR OF THE IRIS*
}

\author{
BY \\ H. O. OBIANWU AND M. J. RAND \\ From the Department of Pharmacology, School of Pharmacy, University of London
}

\section{Introduction}

IT is well known to practising ophthalmologists that ephedrine is less effective as a mydriatic in subjects with deeply coloured irides than in those with light irides. This observation was first reported by Howard and Lee (1927), who stated that there was a distinct difference between Caucasians with light coloured irides and Chinese with dark irides, the former responding to smaller doses, and giving a larger mydriasis which developed more rapidly to equal doses. Chen and Poth (1929a, b) observed that ephedrine was considerably less active in dilating the pupils in Americans of African and Chinese descent than in white Americans. Barbee and Smith (1957) confirmed these findings with American negroes and found that among white Americans, those with hazel, brown, or black irides were less responsive than those with blue, grey, or green irides. However, Sattler (1927) reported that he saw no difference in the mydriatic response of brown, green, or blue irides to ephedrine in Europeans and in one negro subject. We were not able to find any other reports on the mydriatic actions of ephedrine in subjects with different coloured irides and from different ethnic groups, so we took the opportunity to make observations in African, Indian, Chinese, and European students living in a university hall of residence.

\section{Methods}

The sixty men students who volunteered for the experiment were between 18 and 30 years of age. There were twenty Europeans with light coloured irides (blue, grey, and green), ten Europeans with dark irides (hazel and brown), ten Africans, ten Chinese, and ten Indians. The data given in Figs 1 and 2 were obtained from these subjects. Those with known past or present eye disease were excluded. Each student was used only once. Additional experiments were carried out using a few other student volunteers.

Ephedrine was instilled into the conjunctival sac of one eye as two drops of a 3 per cent. solution of the hydrochloride, and the subject then kept his eyes closed for three minutes.

The response was measured one hour after instillation at which time the mydriasis was complete and maintained. The maximum effect is obtained in 40 to 50 minutes according 
to Chen and Poth (1929a), and in 30 to 60 minutes according to Chen and Poth (1929b), who found it to be maintained for three to nine hours. Sattler (1927) reported that the maximal response persisted for two to three hours.

The experiments were carried out in artificial light. The intensity of the light was such as to give a deflection of 10 units on a Weston light meter viewing the same aspect as the subject. The pupil diameter before and after ephedrine was measured from photographs of the eye. These were taken with a Contaflex reflex camera fitted with a $0.2 \mathrm{~mm}$. Proxar lens set for minimum focal length. The camera was then placed to give a sharply focused image of the iris aperture; the camera range-finding system was such that the deviation in distance between the eye and the camera was less than $\pm 1 \mathrm{~cm}$. (in $25 \mathrm{~cm}$.). A millimetre scale was photographed in the same way and pupil diameter was measured from equal projections of the negatives. The subjects were instructed to fix a point directly ahead and about 10 feet away while the photograph was taken.

\section{Results}

The mean mydriatic action of 3 per cent. ephedrine in each of the five groups of subjects is shown in Fig. 1.

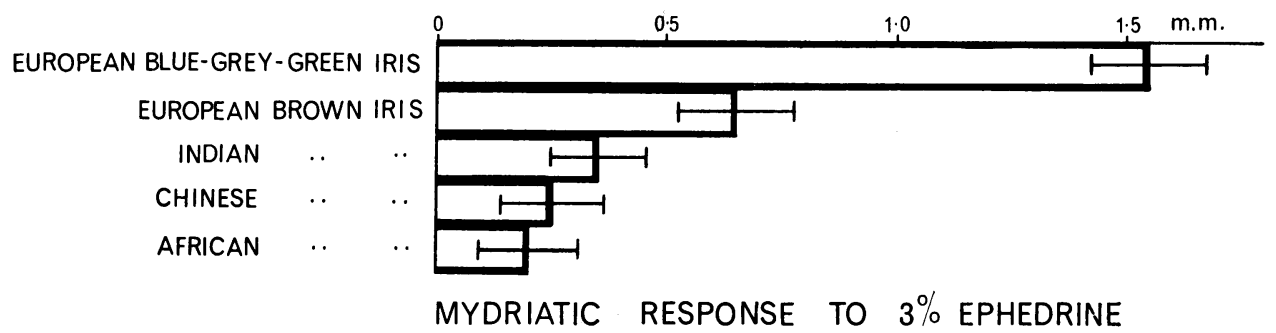

FIG. 1.-Mean mydriatic response to 3 per cent. ephedrine. The horizontal lines at the end of each row indicate the standard errors of the means of the responses.

The Europeans with light coloured irides were the most sensitive and every subject reacted. Europeans with brown irides were considerably less sensitive and one of the 10 did not react. The mean difference in pupillary dilatation between the Europeans with light and dark irides was statistically very highly significant $(\mathrm{P}<0.001 ; t$-test).

The irides of Indian, Chinese, and African subjects were decreasingly less sensitive, but there was no statistical significance in the mean values for the three groups. The mydriatic response was completely absent in four of the Indians, six of the Chinese, and seven of the Africans. The subjective impression was gained that the iris was most heavily pigmented in Africans and that the hue of the irides of Chinese was deeper than that of Indians, but within each of these groups the iris colour was more homogeneous than in the group of Europeans with brown irides; these included subjects with hazel eyes and rays of blue-grey colour in the periphery of the iris, although they were selected as being predominantly brown.

The difference in mean mydriatic response between Europeans with brown eyes and Indians was statistically not significant $(0 \cdot 1>\mathrm{P}>0.05 ; t$-test $)$; the difference between brown-eyed Europeans and Africans was significant $(0.02>\mathrm{P}>0.01 ; t$-test). From these considerations it may be concluded that the relationship between the depth of colour of the iris and the response to ephedrine depends on the race of the subject only to the extent that this is a determinant of the degree of pigmentation of the iris. 
It would have been desirable to make observations with a range of concentrations of ephedrine, and in particular to use high concentrations to determine whether the brown irides which did not respond to 3 per cent. ephedrine were relatively or absolutely insensitive. In preliminary experiments it was established that 1 per cent. ephedrine caused a weaker mydriatic reaction and was effective in a smaller proportion of subjects and 10 per cent. ephedrine was too painful to justify its use for these experiments. Howard and Lee (1927) reported that strong solutions of ephedrine caused a stinging and burning sensation and the subjects developed headache. Nevertheless they were able to state that the mydriatic response to 5 per cent. ephedrine in Caucasians could be approximately equalled in Chinese with 20 per cent. ephedrine. Chen and Poth used a 10 per cent. solution and reported that it sometimes caused a stinging sensation.

A comparison of the present data with other published quantitative observations is given in Table I. Our Caucasian subjects gave a smaller response than did those of

TABLE I

COMPARISON WITH PUBLISHED DATA ON EPHEDRINE MYDRIASIS

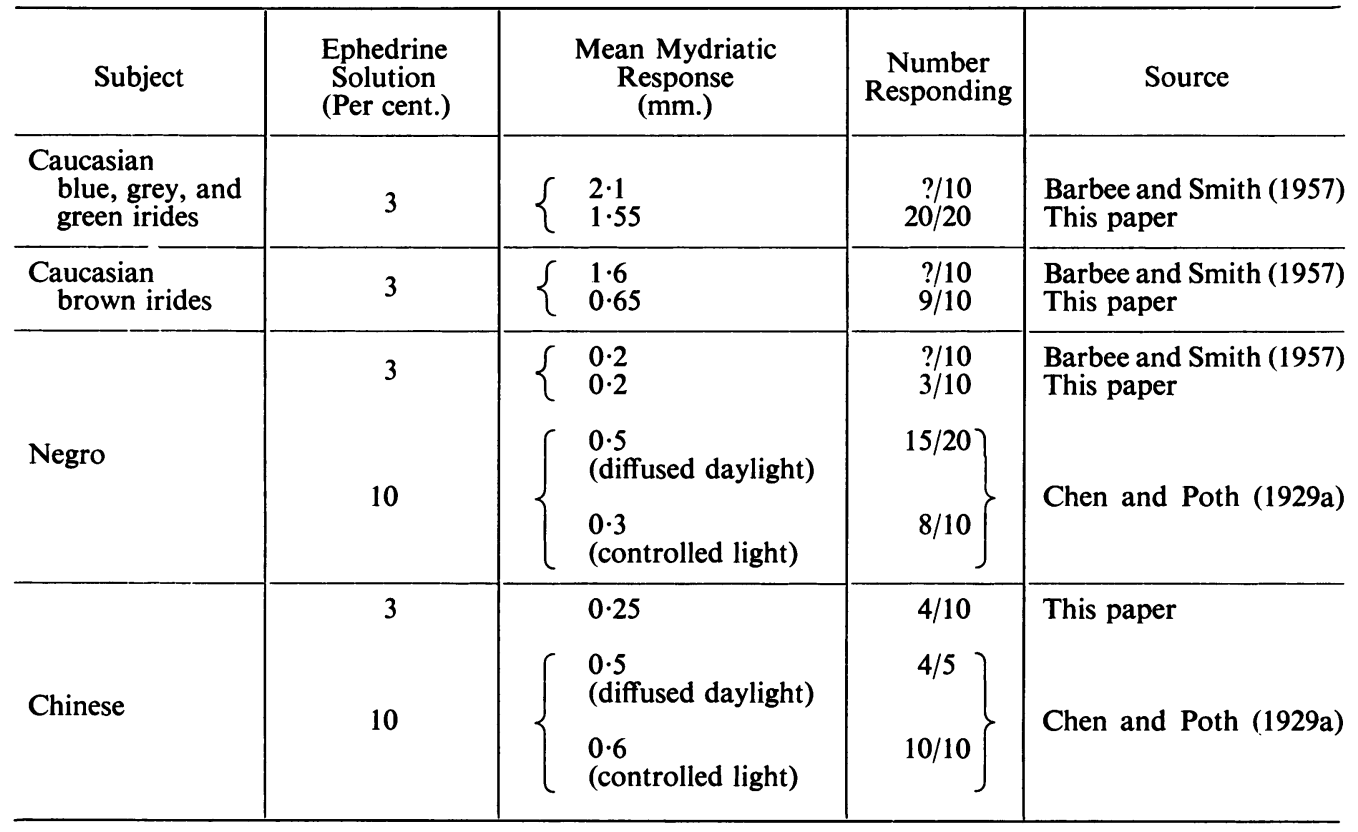

Barbee and Smith (1957), although the results with negro subjects were the same. Chen and Poth (1929a), using a stronger solution of ephedrine, obtained a greater mean mydriasis with a larger proportion of subjects responding in both negro and Chinese subjects; this suggests that these subjects are relatively insensitive to ephedrine, rather than absolutely insensitive.

While the results were being collated it was noticed that the resting pupil diameter was smaller in subjects who failed to respond or gave poor responses to ephedrine than in those who responded well. The relationship between the mydriatic response and the resting pupil diameter is shown in Fig. 2. 


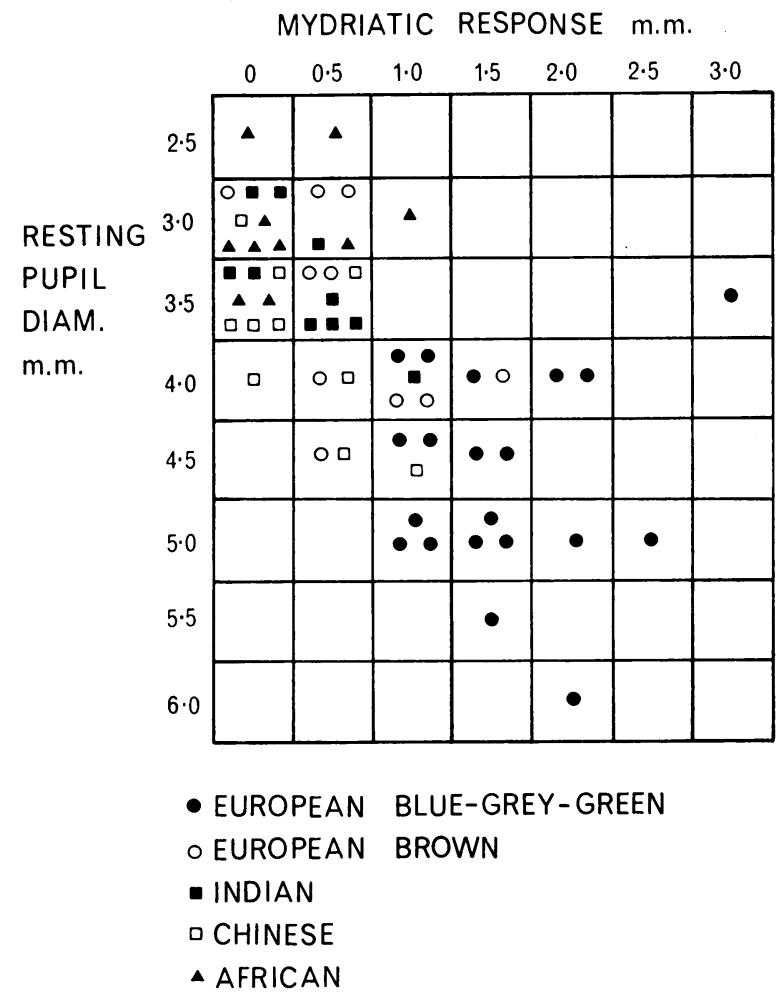

FIG. 2.-The relationship between the resting pupil diameter and the mydriatic response to 3 per cent. ephedrine in 60 subjects. The correlation coefficient $(r)$ is +0.65 .

The correlation coefficient $(r)$ is +0.65 , which is statistically highly significant $(\mathrm{P}<0 \cdot 01)$. It also follows from these data that the resting pupil diameter is inversely related to the degree of pigmentation of the iris.

This observation suggested an explanation for the insensitivity to ephedrine of deeply pigmented irides. Ephedrine produces mydriasis without blocking the pupillary light reflex (Chen and Schmidt, 1930). Our subjects were all tested in equal conditions of illumination, therefore there must be differences in the resting level of the light reflex. This may be due either to differences in the levels at which the reflex is "set" in the central nervous system or to differences in the responsiveness of the constrictor pupillae to the nervous control. If this is so, it would be expected that the irides which are refractory to ephedrine may respond when the parasympathetic nervous drive leading to miosis is impaired. This was tested in a small group of students when homatropine $(0.25$ per cent.) was instilled into one eye and one hour later two drops of 3 per cent. ephedrine were instilled into each eye. The results given in Table II show that the mydriatic action of ephedrine in more heavily pigmented irides is more clearly evident after paralysis of the parasympathetic tone with homatropine. In light coloured irides ephedrine was less effective after homatropine, but this may be because the irides had an initially greater diameter and after homatropine they were approaching a maximal mydriasis. 
TABLE II

- EFFECT OF HOMATROPINE ON THE MYDRIATIC ACTION OF EPHEDRINE

\begin{tabular}{|c|c|c|c|}
\hline \multirow{2}{*}{ Iris Colour } & \multicolumn{3}{|c|}{$\begin{array}{l}\text { Mydriatic Response } \\
(\mathrm{mm} .)\end{array}$} \\
\hline & Homatropine & $\begin{array}{l}\text { After Ephedrine } \\
\text { (Untreated Eye) }\end{array}$ & $\begin{array}{l}\text { After Ephedrine } \\
\text { (Homatropine Eye) }\end{array}$ \\
\hline Brown & $\begin{array}{l}2,2,1 \cdot 5,1,1 \\
(\text { mean }=1 \cdot 5)\end{array}$ & $\begin{array}{c}0.5,0,1,0,1 \\
(\text { mean }=0.5)\end{array}$ & $\begin{array}{c}1 \cdot 5,1,1,2,1 \cdot 5 \\
(\text { mean }=1 \cdot 4)\end{array}$ \\
\hline Blue, grey, green & $\begin{array}{c}2,2,1.5 \\
(\text { mean }=1.8)\end{array}$ & $\begin{array}{c}1 \cdot 5,1,1 \cdot 5 \\
(\text { mean }=1 \cdot 3)\end{array}$ & $\begin{array}{c}0.5,0.5,0 \\
(\text { mean }=0.3)\end{array}$ \\
\hline
\end{tabular}

Chen and Poth (1929b), mention that the use of ephedrine for ophthalmological examination is improved by giving homatropine to make the pupillary light reflex sluggish. Sattler (1927) also stated that the mydriatic response to ephedrine was larger in dim light than in bright light, when the parasympathetic miotic drive would be less.

The resting pupil diameter was not mentioned by Chen and Poth (1929a), although these authors took elaborate precautions to maintain a constant illumination of the eye in every subject. Barbee and Smith (1957), who did not specify the lighting conditions, give data from which it is evident that there was no difference in the resting pupil diameter in their subjects.

\section{Discussion}

The differences in pupil response to ephedrine in subjects of different ethnic groupings has not been attributed to a frank racial difference in any of the research papers on the subject, although it is often stated in textbooks. Chen and Poth (1929a) discuss racial differences in various responses to some other drugs. The pressor responses to ephedrine taken by mouth were reported to be the same in Caucasian, Chinese, and negro subjects (Chen and Poth, 1929a). The mydriatic responses to ephedrine in various varieties of rabbits do not differ according to Chen and Poth (1929a), who used white, black, grey, and brown animals. Amphetamine, which acts in a similar way to ephedrine, was equally mydriatic in albino and pigmented rabbit eyes (Angenent and Koelle, 1953).

Howard and Lee (1927) surmised that the difference between light and dark irides in their responses to ephedrine might be due to obstruction of absorption by pigment cells, and Guist (1921) attributed the lesser mydriatic responsiveness to homatropine of brown irides, compared with light coloured irides, to the mechanical interference by pigment to penetration of the drug into the iris. Angenent and Koelle (1953) suggested that the difference might be due to increased destruction of the sympathetic transmitter in pigmented irides and they found that adrenaline was oxidized more rapidly by homogenates of pigmented irides than of albino irides from rabbits, owing to the presence of a more active catechol-oxidase system.

Differences in the mydriatic action of other drugs in relation to the iris colour have been described. Thus Guist (1921) observed that light irides of Europeans were 
more sensitive to homatropine than were dark, but Barbee and Smith (1957) found homatropine or atropine to be equally effective in white and negro Americans. Chen and Poth (1929a) found that cocaine and Euphthalmine (eucatropine) were less effective in negro than in Caucasian subjects, Chinese being intermediate. Barbee and Smith (1957) reported that Neo-synephrine or Paredrine produced an equal degree of mydriasis in light irides, Caucasian dark irides, and in negro irides. Angenent and Koelle (1953) found that homatropine and eucatropine were less effective in rabbits with pigmented eyes than in albinos.

The sympathomimetic actions of ephedrine are largely mediated by release of noradrenaline from the stores at sympathetic nerve endings (Burn and Rand, 1958). This applies to the mydriatic action since ephedrine and Tyramine, which act similarly on sympathetic effectors, are without mydriatic action after sympathectomy (Burn and Tainter, 1931), and Tyramine has no mydriatic action after reserpine; both sympathectomy and reserpine treatment result in depletion of the noradrenaline stores in the iris (Burn and Rand, 1959). It is possible that the poor mydriatic action of ephedrine in deeply pigmented human irides may be due to a lower content of noradrenaline in the stores in the iris; this may arise because dopa (dihydroxyphenylalanine), which is the biochemical precursor of noradrenaline, may be diverted to form melanin in the pigment cells (see Angenent and Koelle, 1953), or there may be a poor sympathetic innervation in dark irides, but there is no evidence for this. It is unlikely that the smaller pupil size of subjects with deeply pigmented irides compared with those with poorly pigmented irides in equal lighting conditions is due to any deficiency of the sympathetic innervation, since the pupillary light reflex involves only the parasympathetic pathways. A corollary of reducing the mydriatic response to Tyramine by depletion of noradrenaline stores is that noradrenaline then becomes considerably more active (Burn and Rand, 1959), and this applies to other sympathomimetic drugs which act directly on smooth muscle, including Neo-synephrine (Burn and Rand, 1958) which Barbee and Smith (1957) found to produce equal mydriasis in subjects with different coloured irides.

The refractoriness of the deeply pigmented iris to ephedrine mydriasis can be attributed to the counteracting miotic reflex which is probably more powerful in these eyes, since the resting pupil diameter is smaller. This suggestion is supported by the finding that ephedrine is more effective after paralysing the reflex with homatropine. The relationship between the parasympathetic miotic drive and the mydriatic action of atropine was observed in mice by Quinton (1963); mydriasis in the mouse is a commonly used pharmacological test for determining atropine-like activity. When the pupillary light reflex was less active owing to poor ambient lighting atropine produced a greater mydriasis than in bright light. The discordant reports on the relationship between iris colour and the action of various mydriatic drugs may be due to differences in the light conditions.

It remains to explain why in man the dark coloured iris has a smaller aperture than the light coloured iris. It would be expected that the retina would be more intensely illuminated in the latter, and this would result in a smaller pupil. In fact, Angenent and Koelle (1953) observed a smaller pupil diameter in albino than in pigmented rabbit eyes which they explained in this way. A possible explanation of the finding in human subjects may be that iris colour is an evolutionary adaptation which 
developed in the bright light of the low latitudes or was lost in the less intense light of high latitudes. If this is so then it is not surprising that the adaptation has been of the combined mechanisms that govern the amount of light striking the retina rather than to just one of them, and the adaptation has resulted in deeper pigmentation of the iris coupled with a more effective light reflex.

\section{Summary}

The mydriatic action of ephedrine has been compared in European, Indian, Chinese, and African students. The mydriatic response was inversely proportional to the degree of pigmentation of the iris. There is evidence that this difference is due to a more powerful reflex miosis in subjects with pigmented irides.

We are grateful to Dr. W. L. R. Brown of our Department of Pharmacy for preparing the drug solutions and to Mr. D. King for developing the films.

\section{REFERENCES}

Angenent, W. J., and Koelle, G. B. (1953). J. Physiol. (Lond.), 119, 102.

BARBEe, R. F., and SMITH, W. O. (1957). Amer. J. Ophthal., 44, 617.

BURN, J. H., and RAND, M. J. (1958). J. Physiol. (Lond.), 144, 314.

$\longrightarrow$, (1959). Ibid., 147, 135.

and TAINTER, M. L. (1931). Ibid., 71, 169.

Chen, K. K., and Poth, E. J. (1929a). J. Pharmacol. exp. Ther., 36, 429.

$\longrightarrow$ - (1929b). Amer. J. med. Sci., 178, 203.

and SchMIDT, C. F. (1930). Medicine (Baltimore), 9, 1.

GuisT, G. (1921). Wien. med. Wschr., 71, 1055.

HowARD, H. J., and LeE, T. P. (1927). Proc. Soc. exp. Biol. (N.Y.), 24, 700.

QuINTon, R. M. (1963). J. Pharm. Pharmacol., 15, 239.

SATTLER, C. H. (1927). Klin. Mbl. Augenheilk., 79, 524. 